\title{
Leprosy in Bhutan: A Pilot Survey*
}

\author{
J. S. BERKELEY \\ Medical Superintendent, Gida Kom Leprosy Hospital, Bhutan $\dagger$
}

\begin{abstract}
The results of a pilot survey to determine the prevalence of leprosy in two districts of Bhutan showed the rates to be 13.4 per 1000 and 24.8 per 1000 respectively. The age of onset, lepromatous rate, and disability rate were found to be higher than in India.
\end{abstract}

\section{Introduction}

In 1964 the Royal Government of Bhutan invited The Leprosy Mission to co-operate in establishing a leprosy service. This work was begun in 1966 with the building of Gida Kom Leprosy Hospital and the carrying out of a preliminary exploratory survey (Berkeley, 1970).

In the planning of this leprosy service, two main problems were immediately apparent. The first was the absence of demographic data, as no national census had ever been taken, and there was no registration of births or deaths. The first census, in 1969, gave a total population for Bhutan of 1,034,774 (Royal Government of Bhutan, 1970). This figure will serve as a baseline for future demographic analysis, but it will be some years before the errors due to enumeration difficulties are eliminated.

The second problem was the lack of definite information regarding leprosy. Morbidity recording was introduced by the Directorate of Health Services in 1963, and each of the 27 government dispensaries throughout the country submits a monthly return of patients treated-with separate recording of gonorrhoea, syphilis, tuberculosis, leprosy, smallpox, malaria, goitre, helminthiasis, and diarrhoeal diseases. These records were examined over a 3-year period (1966-1968 inclusive), and it was found that for leprosy the total returns for the whole of Bhutan were:

$$
\begin{aligned}
& 1966-666 \text { cases } \\
& 1967-528 \text { cases } \\
& 1968-323 \text { cases }
\end{aligned}
$$

These figures refer to the number of treatments given and not to the number of persons with leprosy; also, $76 \%$ of the total number was reported by 1 of the 7 administrative areas. These figures were thus of little use in the planning of a leprosy service.

\footnotetext{
* Received for publication 8 September, 1971.

$\dagger$ Present address-56 Murrayfield Avenue, Edinburgh, 12, Scotland.
} 


\section{Objectives}

The survey that forms the subject of this paper had 2 main objectives: (1) the investigation of the prevalence of leprosy and the various components of its variability; and (2) the development of field techniques and the training of paramedical workers. From the results, it was hoped that estimates could be made of the size of the leprosy problem in Bhutan, and an assessment obtained of the medical requirements in terms of hospital, clinic, and manpower resources.

\section{METHOD}

Administrative and geographical difficulties made it impracticable to examine a random sample of the population or of the villages. After discussion with the Director of Health Services, it was decided to undertake an extensive pilot survey.

Two administrative districts were selected, and a full survey of both districts carried out (Fig. 1). The basis of selection was one area (Paro District) where the Government believed that the prevalence of leprosy was low, and one area (Lhuntsi District) where leprosy was thought to be a serious public health problem. The main advantages of this fuller survey were (1) that the administrative officials of the district would be fully involved, (2) that a sampling frame could be constructed for use in future surveys, and (3) that the two selected districts would take into account racial differences that might have some bearing on prevalence rates. Although all Bhutanese are originally of Mongolian stock, those in Paro District (West Bhutan) are ethnically different from the people of Lhuntsi District (East Bhutan).

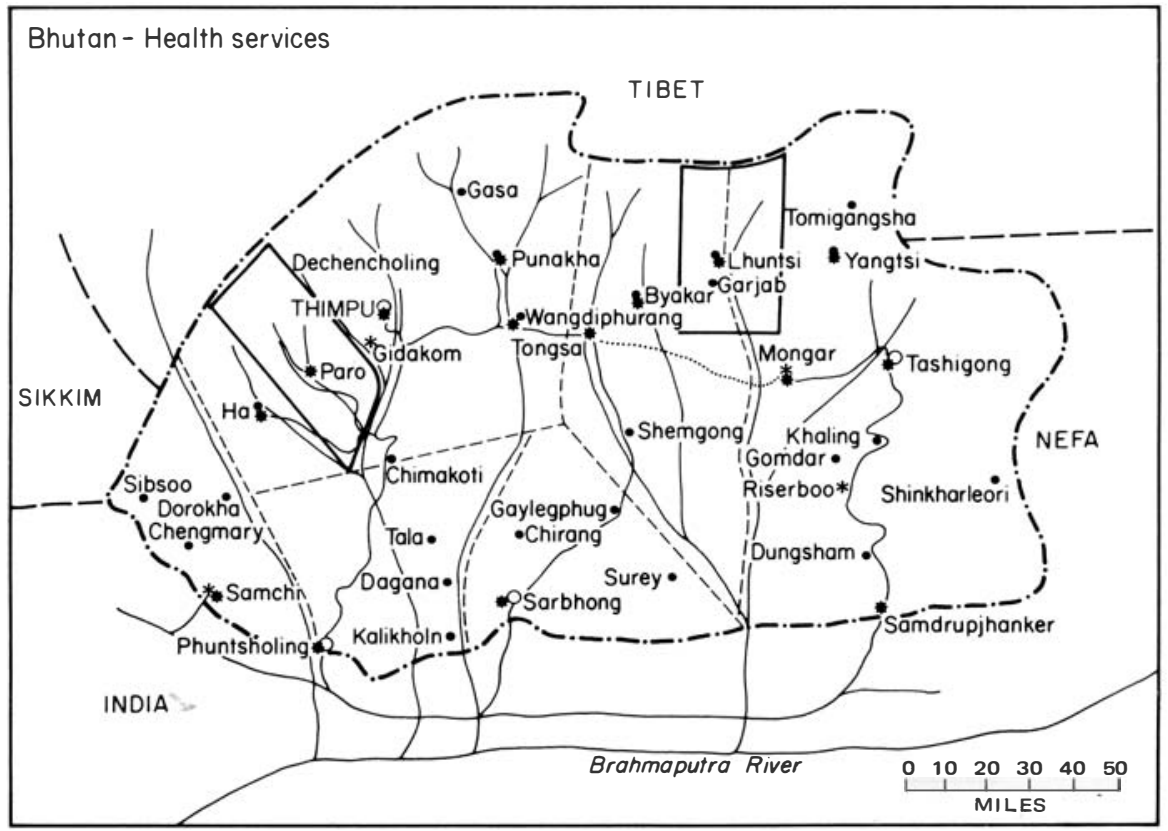

Fig. 1. Survey areas of Paro (West Bhutan) and Lhuntsi (East Bhutan) in boxes. 
These two surveys were carried out in 1969, a similar procedure being followed in each case. The approval of the Government having been obtained, the Director of Health Services informed the district Dzongda (senior administrative official) of the purpose of the survey. About 1 month before the survey, a visit was made to the Dzongda and pamphlets left with him for distribution to village headmen. At the beginning of the survey, each village headman was informed of the expected date of survey of the villages under his jurisdiction. The survey team consisted of a staff of 3 trained members, who travelled from village to village. Communications were easier in Paro District, where no village was more than 2 days' walk from a road, than in Lhuntsi District, where all the villages were 6 to 9 days' walk from a road.

\section{Results}

A total of 14,589 persons were examined in the two districts (Table 1). In Paro District, $79.9 \%$ of the population were examined, and in Lhuntsi District $87.5 \%$.

TABLE 1

Summary of population surveyed

\begin{tabular}{lccccc}
\hline & \multicolumn{2}{c}{$0-14$ years } & \multicolumn{2}{c}{$>15$ years } & \\
& Male & Female & Male & Female & Total \\
\hline Paro & & & & & \\
Population & 1326 & 1349 & 2667 & 3100 & 8442 \\
Examined & 1156 & 1244 & 1730 & 2619 & 6749 \\
Percentage & 87.2 & 92.2 & 64.9 & 84.9 & $79.9 \%$ \\
Lhuntsi & & & & & \\
Population & 1692 & 1590 & 2567 & 3092 & 8941 \\
Examined & 1530 & 1492 & 2026 & 2792 & 7840 \\
Percentage & 90.4 & 93.8 & 78.9 & 90.3 & $87.5 \%$ \\
\hline
\end{tabular}

The demographic difficulties previously mentioned account for some inaccuracy in these figures. The total population figures of each district were provided by the respective Dzongdas, and then checked with village headmen and with individual householders. There were some inconsistencies between these 3 sources of information, but these were not large enough to affect the survey percentages. It was noted that in Paro District only $64.9 \%$ of the adult male population were examined; this was partly due to the fact that a number of men were in South Bhutan, wintering their cattle.

The population structure of the two districts showed the following age distribution:

\begin{tabular}{lccc}
\hline & $0-4$ years & Total under 20 years & 20 years and over \\
\hline Paro & $9.3 \%$ & $36.7 \%$ & $63.3 \%$ \\
Lhuntsi & $12.5 \%$ & $43.5 \%$ & $56.5 \%$ \\
\hline
\end{tabular}

This may be compared with India, where $15 \%$ of the population are in the 0-4 years age-group and 50\% are under 20 years (Gopalan, 1969). 
AGE AND SEX

A total of 285 cases of leprosy were found during the survey-90 in Paro District and 195 in Lhuntsi District. The distribution of these patients by age and sex is shown in Table 2.

Only 9 children under the age of 15 years were found to have leprosy; 2 of these were said to have developed the disease before the age of 5 years. The age of onset was taken as the patient's present age minus the duration of signs or symptoms of leprosy. In 36 cases, leprosy was stated to have been first recognized at over the age of 50 years.

TABLE 2

Age and sex of leprosy patients

\begin{tabular}{|c|c|c|c|c|c|c|}
\hline Age (years) & Male & $\begin{array}{c}\text { Paro } \\
\text { Female }\end{array}$ & Total & Male & $\begin{array}{l}\text { Lhuntsi } \\
\text { Female }\end{array}$ & Total \\
\hline $0-4$ & 0 & 0 & 0 & 0 & 0 & 0 \\
\hline 5-9 & 0 & 0 & 0 & 0 & 2 & 2 \\
\hline $10-14$ & 2 & 2 & 4 & 2 & 1 & 3 \\
\hline $15-19$ & 2 & 0 & 2 & 5 & 1 & 6 \\
\hline $20-24$ & 4 & 4 & 8 & 13 & 6 & 19 \\
\hline $25-29$ & 7 & 9 & 16 & 10 & 8 & 18 \\
\hline $30-34$ & 8 & 5 & 13 & 9 & 13 & 22 \\
\hline $35-39$ & 6 & 2 & 8 & 15 & 9 & 24 \\
\hline $40-44$ & 6 & 0 & 6 & 15 & 9 & 24 \\
\hline $45-49$ & 4 & 3 & 7 & 12 & 9 & 21 \\
\hline Over 50 & 13 & 13 & 26 & 30 & 26 & 56 \\
\hline \multirow[t]{2}{*}{ Total } & 52 & 38 & 90 & 111 & 84 & 195 \\
\hline & \multicolumn{3}{|c|}{$\begin{aligned} 0-14 \text { years } & =4.4 \% \\
15-49 \text { years } & =66.8 \% \\
\text { Over } 50 \text { years } & =28.9 \% \\
\text { Mean age } & =30 \text { years }\end{aligned}$} & \multicolumn{3}{|c|}{$\begin{aligned} 0-14 \text { years } & =2.7 \% \\
15-49 \text { years } & =68.7 \% \\
\text { Over } 50 \text { years } & =28.8 \% \\
\text { Mean age } & =29.25 \text { years }\end{aligned}$} \\
\hline
\end{tabular}

\section{CLASSIFICATION}

The classification of the cases of leprosy, based on clinical criteria, is shown in Table 3.

TABLE 3

Classification of leprosy cases

\begin{tabular}{|c|c|c|c|c|c|c|c|c|}
\hline & \multicolumn{4}{|c|}{ Paro } & \multicolumn{4}{|c|}{ Lhuntsi } \\
\hline & M. & F. & Total & $\%$ & M. & F. & Total & $\%$ \\
\hline Lepromatous & 27 & 17 & 44 & 47.0 & 39 & 22 & 61 & 31.3 \\
\hline Dimorphous & 13 & 10 & 23 & 25.6 & 52 & 52 & 104 & 53.4 \\
\hline Polyneuritic & 1 & 1 & 2 & 2.2 & 1 & 0 & 1 & 0.5 \\
\hline Tuberculoid & 4 & 10 & 14 & 15.5 & 19 & 10 & 29 & 14.8 \\
\hline Indeterminate & 7 & 0 & 7 & 7.8 & 0 & 0 & 0 & 0.0 \\
\hline Total & 52 & 38 & 90 & & 111 & 84 & 195 & \\
\hline
\end{tabular}


It was found that the proportion of cases of tuberculoid leprosy was only $15 \%$ in both districts. The largest groups were the men with lepromatous leprosy in Paro, and men and women with dimorphous leprosy in Lhuntsi. The lepromatous rates were 6.8 per 1000 in Paro, and 7.8 per 1000 in Lhuntsi.

The lepromatous and dimorphous leprosy prevalence rates are shown in Table 4. The sex ratio $(\mathrm{M}: \mathrm{F})$ for lepromatous leprosy in both districts was $2.2: 1$.

TABLE 4

Lepromatous and dimorphous leprosy prevalence rates

\begin{tabular}{|c|c|c|c|c|}
\hline \multicolumn{2}{|c|}{ Classification } & \multirow[t]{2}{*}{ Cases } & \multirow[t]{2}{*}{ Population } & \multirow[t]{2}{*}{ Prevalence (per 1000) } \\
\hline Paro & & & & \\
\hline \multirow{2}{*}{ Lepromatous } & Male & 27 & 2886 & 9.4 \\
\hline & Female & 17 & 3863 & 4.4 \\
\hline \multirow{2}{*}{ Dimorphous } & Male & 13 & 2886 & 4.5 \\
\hline & Female & 10 & 3863 & 2.6 \\
\hline \multicolumn{5}{|l|}{ Lhuntsi } \\
\hline \multirow[t]{2}{*}{ Lepromatous } & Male & 39 & 3556 & 11.0 \\
\hline & Female & 22 & 4284 & 5.5 \\
\hline \multirow{2}{*}{ Dimorphous } & Male & 52 & 3556 & 14.6 \\
\hline & Female & 52 & 4284 & 12.1 \\
\hline
\end{tabular}

This gives a sex ratio ( $\mathrm{M}: \mathrm{F})$ for lepromatous leprosy in both districts of $2.2: 1$.

\section{CLASSIFICATION AND AGE AT ONSET}

Classification was related to age at onset of leprosy (Table 5); 9 cases were omitted from this table, as these patients were uncertain about the age at onset. The patients with polyneuritic and indeterminate leprosy were not included in the Table, since there were only 9 of them. It was found that the modal age of onset is in the 25-29 years age-group in Paro, and in the 20-24 years age-group in Lhuntsi.

\section{DISABILITY}

Disability was recorded and graded according to the World Health Organization (WHO) method of classification (WHO, 1960). In Table 6 only the disabilities of hands and feet are considered, as these relate to the ability to be self-supporting.

In Paro District, 2 patients (2.2\%) were blind in one eye and in Lhuntsi District 5 patients $(2.6 \%)$ were blind in one eye. This compares with the finding that approximately $1 \%$ of the general population of Bhutan are blind in one eye (Berkeley, 1969).

The large number of patients in Lhuntsi with disability of Grade 4 or 5 was noted $-32.8 \%$, as compared with $23.9 \%$ in Paro-and this is particularly in those with dimorphous leprosy.

\section{CONTACT}

All patients were questioned regarding their contact with known cases of leprosy, either in the family or in the village. The replies are shown in Table 7. 
TABLE 5

Classification and age at onset

\begin{tabular}{|c|c|c|c|c|c|c|c|c|c|}
\hline \multirow[b]{2}{*}{ Age (years) } & \multicolumn{3}{|c|}{ Lepromatous } & \multicolumn{3}{|c|}{ Dimorphous } & \multicolumn{3}{|c|}{ Tuberculoid } \\
\hline & M. & F. & Total & M. & F. & Total & M. & $\mathrm{F}$. & Total \\
\hline \multicolumn{10}{|l|}{ Paro } \\
\hline $0-4$ & 0 & 0 & 0 & 0 & 0 & 0 & 0 & 0 & 0 \\
\hline $5-9$ & 0 & 1 & 1 & 0 & 1 & 1 & 0 & 0 & 0 \\
\hline $10-14$ & 1 & 2 & 3 & 0 & 1 & 1 & 1 & 1 & 2 \\
\hline $15-19$ & 4 & 1 & 5 & 2 & 2 & 4 & 0 & 2 & 2 \\
\hline $20-24$ & 4 & 3 & 7 & 1 & 0 & 1 & 0 & 0 & 0 \\
\hline $25-29$ & 5 & 5 & 10 & 3 & 2 & 5 & 0 & 0 & 0 \\
\hline $30-34$ & 2 & 1 & 3 & 2 & 0 & 2 & 0 & 1 & 1 \\
\hline $35-39$ & 5 & 0 & 5 & 1 & 1 & 2 & 0 & 2 & 2 \\
\hline $40-44$ & 2 & 1 & 3 & 0 & 0 & 0 & 0 & 2 & 2 \\
\hline 45-49 & 1 & 1 & 2 & 1 & 0 & 1 & 0 & 1 & 1 \\
\hline Over 50 & 1 & 2 & 3 & 2 & 2 & 4 & 0 & 0 & 0 \\
\hline Total & 25 & 17 & 42 & 12 & 9 & 21 & 1 & 9 & 10 \\
\hline \multicolumn{10}{|l|}{ Age (years) } \\
\hline Lhuntsi & & & & & & & & & \\
\hline $0-4$ & 0 & 0 & 0 & 0 & 1 & 1 & 1 & 0 & 1 \\
\hline $5-9$ & 1 & 1 & 2 & 2 & 4 & 6 & 0 & 3 & 3 \\
\hline $10-14$ & 1 & 1 & 2 & 4 & 5 & 9 & 5 & 1 & 6 \\
\hline $15-19$ & 2 & 4 & 6 & 8 & 8 & 16 & 1 & 1 & 2 \\
\hline $20-24$ & 3 & 4 & 7 & 11 & 11 & 22 & 3 & 2 & 5 \\
\hline $25-29$ & 7 & 1 & 8 & 5 & 5 & 10 & 3 & 0 & 3 \\
\hline $30-34$ & 9 & 3 & 12 & 9 & 4 & 13 & 2 & 0 & 2 \\
\hline $35-39$ & 8 & 3 & 11 & 5 & 3 & 8 & 1 & 2 & 3 \\
\hline $40-44$ & 1 & 0 & 1 & 3 & 1 & 4 & 0 & 0 & 0 \\
\hline $45-49$ & 0 & 2 & 2 & 1 & 2 & 3 & 0 & 0 & 0 \\
\hline Over 50 & 7 & 3 & 10 & 4 & 8 & 12 & 3 & 1 & 4 \\
\hline Total & 39 & 22 & 61 & 52 & 52 & 104 & 19 & 10 & 29 \\
\hline
\end{tabular}

Considering that there is very little social ostracism of the leprosy patient in Bhutan, it is perhaps surprising that in Paro more than half the patients acknowledged no known contact. Twice as many of the patients in Lhuntsi gave a history of family contact, when compared with those from Paro District.

\section{PREVIOUS TREATMENT}

Only 87 of the patients in the two districts had ever had any treatment for their leprosy; $69 \%$ of patients had at some time been to either Gida Kom Leprosy Hospital, Kalimpong Leprosy Hospital, Garjab Leprosy Clinic or a Government dispensary, though in many cases this had been some years previously and for only one attendance.

\section{Discussion}

From this survey it was found that the prevalence rate for leprosy in Paro District was 13.4 per 1000 and in Lhuntsi District it was 24.8 per 1000. (This compares with India, where a "high" prevalence rate is taken as over 5 per 1000, 
TABLE 6

Classification and disability grading

\begin{tabular}{|c|c|c|c|c|c|c|c|c|c|c|c|c|}
\hline Paro & M. & F. & Total & $\%$ & M. & F. & Total & $\%$ & M. & F. & Total & $\%$ \\
\hline Lepromatous & 12 & 7 & 19 & 22.5 & 10 & 4 & 14 & 16.7 & 3 & 4 & 7 & 8.4 \\
\hline Dimorphous & 3 & 1 & 4 & 4.9 & 4 & 4 & 8 & 9.6 & 5 & 4 & 9 & 10.7 \\
\hline Tuberculoid & 1 & 5 & 6 & 7.1 & 3 & 1 & 4 & 4.8 & 0 & 4 & 4 & 5.8 \\
\hline \multicolumn{13}{|l|}{ Lhuntsi } \\
\hline Lepromatous & 18 & 10 & 28 & 14.6 & 10 & 6 & 16 & 8.3 & 10 & 6 & 16 & 8.3 \\
\hline Dimorphous & 17 & 18 & 35 & 18.3 & 18 & 7 & 25 & 13.0 & 17 & 27 & 44 & 23.0 \\
\hline Tuberculoid & 11 & 7 & 18 & 9.3 & 4 & 2 & 6 & 3.1 & 2 & 1 & 3 & 1.5 \\
\hline Total & & & & $42.2 \%$ & & & & $21.7 \%$ & & & & $32.8 \%$ \\
\hline
\end{tabular}


TABLE 7

History of contact

\begin{tabular}{|c|c|c|c|c|c|c|c|c|c|}
\hline \multirow[b]{2}{*}{ Paro } & \multicolumn{3}{|c|}{ Family } & \multicolumn{3}{|c|}{ Village } & \multicolumn{3}{|c|}{ Not known } \\
\hline & M. & F. & Total & M. & F. & Total & M. & F. & Total \\
\hline Lepromatous & 3 & 6 & 9 & 9 & 7 & 16 & 15 & 4 & 19 \\
\hline Dimorphous & 2 & 2 & 4 & 4 & 0 & 4 & 7 & 8 & 15 \\
\hline Tuberculoid & 1 & 0 & 1 & 1 & 3 & 4 & 2 & 7 & 9 \\
\hline Total & & & $17.8 \%$ & & & $30 \%$ & & & $52.3 \%$ \\
\hline \multicolumn{10}{|l|}{ Lhuntsi } \\
\hline Lepromatous & 13 & 11 & 24 & 19 & 6 & 25 & 7 & 5 & 12 \\
\hline Dimorphous & 13 & 24 & 37 & 26 & 20 & 46 & 13 & 8 & 21 \\
\hline $\begin{array}{c}\text { Tuberculoid } \\
\text { Total }\end{array}$ & 6 & 6 & $\begin{array}{c}12 \\
37.4 \%\end{array}$ & 3 & 3 & $\begin{array}{c}6 \\
39.4 \%\end{array}$ & 10 & 1 & $\begin{array}{c}11 \\
23.3 \%\end{array}$ \\
\hline
\end{tabular}

such areas being found mainly in eastern parts of India and between them accounting for about three-quarters of the total leprosy in India.) If these rates are applied to the estimated total population of Bhutan, there could be about 11,000 cases of leprosy in the country.

It is interesting to note that the age of onset of leprosy is apparently later in Bhutan than in many other countries, where the majority of patients show the first manifestations of leprosy before the age of 20 years (Cochrane, 1964). When this is taken in conjunction with the age-structure of the population, it would appear that the main emphasis in future survey work should be on school-leavers and such organized groups as police, monks, the army, and the labour force. The male : female sex ratio of $2: 1$ for lepromatous disease in the population aged 20-39 years would appear to indicate a potential source of spread of the disease, since it is men in this group who are likely to be found in the organizations mentioned above, or moving about the country in the course of their normal agricultural and trade customs.

Job (1965) has stated that in India lepromatous leprosy accounts for 13 to $15 \%$ of cases and in China it is thought to be about 40 to $45 \%$ of the total cases. From the survey figures here reported, it is seen that the corresponding figures are $47 \%$ for Paro and $31.3 \%$ for Lhuntsi. This would support the view that people of Mongolian extraction are more likely to develop lepromatous leprosy than inhabitants of India. The large number of patients with dimorphous leprosy in Lhuntsi would account for the high disability rate seen in that district.

Estimates of the frequency of disabilities vary considerably-from $10 \%$ in Burma (Mallac, 1962) to 29.2\% in Bombay (Chodankar, 1962)-and are related to the pattern of the disease and the standards of medical care in different countries. In this survey a high rate of disability was found. About $54 \%$ of patients had some degree of disability (Grade 2-5), and of these, half were severely disabled (Grade 4-5). If these figures apply to the whole of Bhutan, there may be about 3000 people (about $1 \%$ of the adult population) who are so disabled that they are unable to support themselves.

It is encouraging to find that nearly $70 \%$ of the leprosy patients who were seen had at some time or other sought treatment. This would seem to indicate a willingness to accept modern methods of treatment, but the sporadic attendance 
at clinics reveals the need to organize some kind of education and follow-up of all cases. To some extent this would mean the creation of leprosy clinics, but there are already Government Health Service dispensaries throughout Bhutan where treatment could be given. With this in view, a handbook on the diagnosis and treatment of leprosy has been circulated to all Government Medical Officers and Compounders (1970), and a simple pamphlet in both English and Bhutanese produced for general distribution.

This survey has provided the basis for certain recommendations regarding the organization of a leprosy service in Bhutan. The magnitude of the problem in Bhutan can be appreciated when one considers the thinly populated, mountainous region and the scarcity of trained doctors and auxiliaries. The present survey facilitated the training of medical auxiliary staff in leprosy work, and enabled various forms and procedures to be tried in the field.

\section{Acknowledgements}

I wish to thank Dasho (Dr.) Tobgyel, Director of Health Services, Royal Government of Bhutan, for permission to publish this article; and to acknowledge my indebtedness to The Leprosy Mission, London, for their support and encouragement.

\section{References}

Berkeley, J. S. (1969). Medical practice in Bhutan. Practitioner 203, 791.

Berkeley, J. S. and Berkeley, M. I. K. (1970). Preliminary report on leprosy in Bhutan. Int. J. Lepr. 38, 78.

Chodankar (1962). Quoted by Mallac, M. J. (1966). Lepr. Rev. 37, 71.

Cochrane, R. G. (1964). Epidemiology. In Leprosy in Theory and Practice, 2nd ed., p. 76. Bristol, John Wright \& Sons.

Gopalan, C. (1969). Nutrition and Family Planning. J. Christian Med. Assoc. India 44, 494.

Job, C. K. (1965). An outline of pathology of leprosy. Int. J. Lepr. 33, 533.

Mallac, M. J. (1962). Disability in leprosy WHO/SEARO/LEP. 11, 1-14.

Royal Government of Bhutan (1969). Census Report.

Royal Government of Bhutan (1970). Handbook on Leprosy in Bhutan.

World Health Organization (1960). Expert Committee on Leprosy. WHO Tech. Rep. Series No. 189. 